\title{
Finite element analysis of the folding process of creased white-coated paperboard using a combined fluffing resistance and shear yield glue model
}

\author{
Weerayut JINA* and Shigeru NAGASAWA* \\ *Department of Mechanical Engineering, Nagaoka University of Technology, \\ 1603-1 Kamitomioka, Nagaoka 940-2188, Niigata, Japan \\ E-mail: snaga@mech.nagaokaut.ac.jp
}

Received: 25 December 2017; Revised: 23 April 2018; Accepted: 29 May 2018

\begin{abstract}
This study aims to develop a numerical simulation model of the folding process of a creased paperboard and to reveal the deformation characteristics of the creased paperboard. A cantilever type bending moment measurement apparatus was experimentally examined with a $0.43-\mathrm{mm}$ thickness paperboard. To verify the folding mechanics of the creased part, the initial crease was varied within a certain range, and the lamination numbers were considered with 8 layers. A fluffing resistance model based on the z-directional (out-of-plane) tensile test was developed and simulated using isotropic elasto-plastic solid properties. However, because the fluffing resistance is restricted in the normal direction of the detached interface, in-plane shear resistance is not considered. When investigating the folding process of a creased part, the in-plane shear resistance and its breaking limit seem to be the primary characteristics. Therefore, in this work, in order to characterize the delamination and bulging deformation, an internal breaking criteria was numerically analyzed using a new combination model. A general purpose finite element method (FEM) code was applied to develop a combination model comprising the out-of-plane fluffing subroutine and the in-plane shear glue strength. Through the FEM simulation of the folding process of creased paperboards, the following results were revealed: (1) The simulated bulging profile of the creased part and its bending moment resistance well matched with the corresponding experimental result at the stationary folding state with a folding angle $>20^{\circ}$. (2) The in-plane shear glue strength characterizes the pattern of the interlayer delamination in the folding process of the scored zone. (3) The initial delaminated span of the scored zone is estimated as $>150 \%$ of the creasing width. (4) The initial gradient of the bending moment resistance is characterized by the scored depth.
\end{abstract}

Keywords : Bending, Folding, Delamination, Bulging, In-plane shear strength, FEM, Fluffing, Scored depth

\section{Introduction}

Coated paperboard is widely used in the packaging industry owing to its benefits such as a high strength-to-weight ratio, high surface smoothness, printability, sustainability and recyclability. In the production of packaging containers, wedge-pushed cutting, creasing by the flatbed die cutter and the folding of creased lines are inevitable and determine the quality of containers (Kirwan, 2013). In the formation of blank patterns made of paperboard, a suitable residual stiffness of the creased parts is necessary for processing the fold of the paperboard in an automatic folder-gluer machine, and the creased lines must be stably folded without any surface failures. Namely, the creaser indentation depth against the paperboard must be controlled to retain the folding strength of the creased lines and the appropriate bulge that forms in the fold's interior. These procedures were empirically managed by experts in the past. However, to process this formation automatically in the folder-gluer machine, an appropriate prediction of the folding stiffness and the bulge profile with the specified creaser indentation depth is required.

Regarding the estimation of the crease deviation in the folds of eccentrically creased paperboards and the quasistatic folding stiffness concerning the creaser indentation depth were reported by (Nagasawa et al., 2001, 2008). Some bending strength testers were developed to investigate the bending moment and to record the deformation profile of the creased 
part during a folding process (Nagasawa et al., 2001, 2003, 2011, 2016). One of the bending moment measurement apparatuses (CST-J-1, Katayama Steel Rule Die Inc., Tokyo, Japan) is effective for controlling the bending rotation velocity and its sleeping time at a specified angle position of the creased part of a worksheet (CST-J-1, 2013; Nagasawa et al., 2015). Beex et al. (2009) proposed an FEM cohesive damage model for describing the bulging of the creased part to explain the delamination and folding resistance of a creased paperboard. Sudo et al. (2005) reported a feasibility study about the effect of inner detachment behavior on creasing deformation of a paperboard using a distributed resistance model of nonlinear springs, which was described in the MARC subroutine: USPRNG (MSC software, 2003, 2010a, 2010b); however, Sudo's model did not discuss the shear resistance. Giampieri et al. (2011) reported an FEM model of a delaminated interface for simulating the folding behavior of a creased paperboard, which was considered the evolution of the damage variable with the imposed rotation angle. Hicks et al. (2003) proposed an FEM model to measure the internal energy during the delamination and buckling of laminated materials.

Regarding the delamination behavior of weak-bonded layers of white-coated paperboard, Jina et al. (2017) reported the fluffing model comprising anaphase yielding resistance derived from the $z$-directional tensile test (ZDTT) (Scandinavian Pulp, Paper and Board Testing Committee-SCAN-P, 1998), and the applicability of fluffing resistance to describe the peeling behavior of the weak-bonded layer was discussed using the FEM simulation. Here, although several reports used the orthotropic elastic or the orthotropic elastic-plastic model for simulating the limited cases (Murayama et al., 2005, Nagasawa et al., 2006, 2013a, 2013b; Komiyama et al., 2013), they were sometimes unstable for converging the numerical calculation, especially for a large deformation such as a folding. Therefore, in the previous work (Jina et al., 2017), the material properties of a paperboard were based on the isotropic elastic model with the in-plane compressive properties (the ring crush test), but the delamination of interlayers was considered by using the fluffing resistance of ZDTT. Because the fluffing model was relatively stable for peeling interlayers, it seems to be applicable to other deformations such as a large folding of paperboard after scoring by the creasing rule.

According to the development of the peeling model (Jina et al., 2017), because the glue model comprised a normal yield and the shear yield stress was unstable and far different from the real resistance, glue based detaching was not suitable for simulating the peeling process of a paperboard. However, a certain shear resistance near the peeled edge was necessary for successfully executing the fluffing-model-based simulation, although the peeling force was almost unaffected by the in-plane shear resistance. So far, to apply the fluffing model to the folding deformation of the creased part, a new consideration of the shear resistance in the delaminated layers must be investigated.

In this work, the bending characteristics of a white-coated paperboard, which was previously subjected to the creasing rule indentation, was numerically investigated under the cantilever type folding, to develop a deformation model of the creased part of the paperboard. An FEM model was developed to simulate the bulging deformation and bending moment response of CST-J-1. To develop a mechanical model of detaching resistance of the delaminated layers of paperboard, a combination of the normal-directional fluffing resistance, which was implemented by the use of a MARC user's subroutine USPRNG based on ZDTT, and the in-plane shear yielding stress was introduced. The peeling model (Jina et al., 2017) was not affected by the in-plane shearing resistance, because the peeling force was mainly determined by the out-of-plane (normal directional) detaching stress and the bending stiffness of the peeled thin layer. However, in the case of the folding of a creased part, the bulged crease zone tends to be detached (same as the peeled state), whereas the folded inside left-right zones are a little out of the creased position. They are compressed in the thickness direction and are sheared/slide in the in-plane direction for each laminated layer. Hence, the authors investigated a combination model comprising the fluffing normal resistance (derived from ZDTT) and the glue breaking resistance as the shear yielding stress (based on the in-plane shear test and the frictional shear sliding) for discussing a couple of creasing conditions. Here, to verify the bending behavior of multiple plies, the effects of layer numbers were discussed. The initial creasing process with the creasing rule indentation depth and the folding process as a cantilever type (CST-J-1 model) were also investigated in the FEM simulation and were compared with the experimental results.

\section{Analysis conditions, estimated methods and the mechanical model of worksheet \\ 2.1 Specimens}

A white-coated paperboard comprises a pulp fiber structure matrix and a clay coated layer. The fiber layer comprises multiple plies and the coated layer is a mixture of ground calcium carbonate, kaolin and a binder (Reinhard et al., 2013). In this work, a commercially recycled white-coated paperboard with a thickness $t=0.43(0.42-0.44)$ mm and a nominal basis weight of $350 \mathrm{~g} \cdot \mathrm{m}^{-2}$ was chosen. Its fiber and pulp analyses were summarized in Table 1, whereas the in-plane 
tensile properties of the paperboard in the machine direction of paper making (MD) were shown in Table 2. The specimens were prepared as a rectangle sheet, the width of which was $15 \mathrm{~mm}$, the length was $220 \mathrm{~mm}$, and the gauge length (distance of fixtures) was $180 \mathrm{~mm}$. These mechanical properties were almost the same as that reported in the previous work (Jina et al., 2017).

Table 1 Size of fiber and the pulp combination ratio of white-coated paperboard 350 (measured by Kajaani-FS300) LBKP: Broad-leaved lumber (hard wood), bleaching kraft pulp; N-BKP: Needle-leaved lumber (soft wood), bleaching kraft pulp; NTMP: Needle-leaved, thermal mechanical pulp; L(n): based on number of fibers in each fibrillation index class; L(1): based on length weighted number of fibers in each fibrillation index class; L(w): based on weight-weighted number of fibers in each fibrillation index class; CWT: Wall thickness of cell; Width: average width of fiber ( Jina et al., 2017).

\begin{tabular}{l|l|l|l|l|l|l|l|l|l}
\hline \hline Unit & \multicolumn{4}{l|}{ Pulp combination ratio/\% } & \multicolumn{4}{l|}{ Projected length of fiber/mm } & \multicolumn{2}{l|}{ Size/ $\mu \mathrm{m}$} & \multicolumn{2}{l}{ Section ${\text { area/ } / \mathrm{m}^{2}}^{2}$} \\
\hline Item & L-BKP & N-BKP & N-TMP & L(n) & L(l) & L(w) & Width & CWT & CSA \\
\hline Value & 64.7 & 16.0 & 19.3 & 0.56 & 0.99 & 1.52 & 18.2 & 4.8 & 256.6 \\
\hline
\end{tabular}

Table 2 In-plane tensile properties of a white-coated paperboard in machine direction (MD). Tensile feed velocity was $0.33 \mathrm{~mm} \cdot \mathrm{s}^{-1}$ (strain rate: $0.00183 \mathrm{~s}^{-1}$ ). The tensile procedure was based on JIS-P8113. The average (minimum maximum) of five samples was shown.

\begin{tabular}{l|l|l|l|l}
\hline \hline & $\begin{array}{l}\text { Young's modulus } \\
E / \mathrm{MPa}\end{array}$ & $\begin{array}{l}\text { Yield strength } \\
\sigma_{\mathrm{Y}} / \mathrm{MPa}\end{array}$ & $\begin{array}{l}\text { Tensile strength } \\
\sigma_{\mathrm{B}} / \mathrm{MPa}\end{array}$ & $\begin{array}{l}\text { Breaking strain } \\
\varepsilon_{\mathrm{B}}\end{array}$ \\
\hline $\mathrm{MD}$ & $5400(5350-5460)$ & $27.2(26.6-27.6)$ & $43.2(42-43.86)$ & $0.021(0.02-0.022)$ \\
\hline
\end{tabular}

\subsection{Out-of-plane detaching resistance model of specimens based on ZDTT}

Regarding the out-of-plane (the thickness direction) detaching resistance, the ZDTT model was used for fixing the detaching layers (the interfaces of plies) of the paperboard. Jina et al. (2017) reported the ZDTT relation between the tensile stress and elongation in the thickness direction, as shown in Fig. 1. Figure 1 (a) indicates the schematic of the experimental apparatus of ZDTT. An acrylic-based double-sided adhesive tape NWK-15S was inserted beneath the lower and upper worksheet for stacking the lower crosshead. The feed velocity in the experiment of ZDTT was chosen as 0.1 $\mathrm{mm} \cdot \mathrm{s}^{-1}$. In this report, the specimens were prepared in 10 pieces as a square sheet with a length of $L_{\mathrm{ZDTT}}=10 \mathrm{~mm}$, a width of $B_{\text {ZDTT }}=10 \mathrm{~mm}$ and a thickness of $0.45 \mathrm{~mm}$. In this work, the average thickness of the paperboard was updated as $0.43 \mathrm{~mm}$, due to a new population. Figure 1 (b) shows the tensile stress response diagram of the ZDTT and shows the fitting state between the experimental data and approximation curves. Here, the elongation $e_{z}$ was subdivided into three zones: zone1, zone2 and zone3 as shown in Fig. 1 (b). Here, $e_{\mathrm{z}}(=x)$ is equal to a displacement of the lower crosshead. The tensile stress $\sigma$ was approximated with $e_{z}$ by using Eqs. (1)-(3) (Jina et al., 2017). Table 3 shows the coefficient values of Eqs. (1)-(3). The generated thickness of weak-bonded layer was estimated as $t_{\mathrm{p} \text { ZDTT }}=0.11(0.10-0.11) \mathrm{mm}$. The first zone of $0<e_{\mathrm{z}}<e_{\mathrm{z} 1}$ shows the elastic or elasto-plastic behavior before breaking at the weak-bonded layer. The zone of second and third periods of $e_{\mathrm{z} 1}<e_{\mathrm{z}}<e_{\mathrm{z} 3}$ is a sort of an anaphase yielding behavior that is caused by the fluffing resistance of delamination.

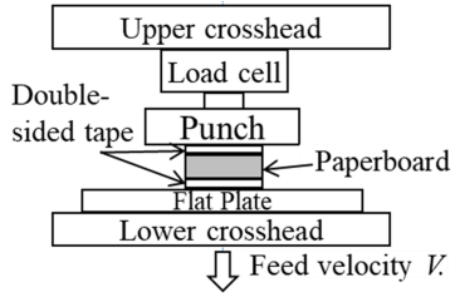

(a) Schematic of experimental apparatus of ZDTT

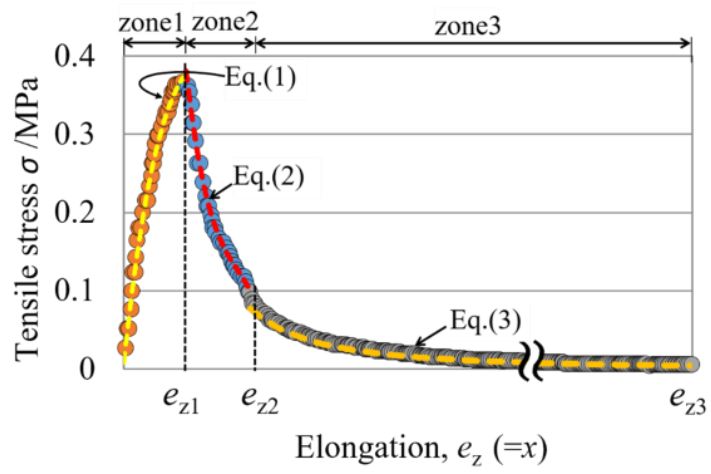

(b) Tensile stress response diagram of ZDTT

Fig. 1 Relations between the tensile stress and elongation in the thickness direction (Jina et al., 2017) $(t=0.45 \mathrm{~mm})$ 
The nominal tensile stress $\sigma$ is described with the detaching distance of $e_{\mathrm{z}}$ as Eqs.(1)-(3), and this seems to be caused by fluffing or the drawing phenomena of fibers. Therefore, the anaphase yielding resistance of ZDTT is applied to the resistance of detaching layers during a folding process of the creased part. This fluffing model can be described using a user-defined subroutine of USPRNG (MSC software, 2010a, 2010b). Here, all the side edges of specimen were simply cut off by using a shaving knife, and any additional notches were not processed on the side edges.

$$
\begin{aligned}
& \sigma=a_{1} e_{\mathrm{z}}^{3}+a_{2} e_{\mathrm{z}}^{2}+a_{3} e_{\mathrm{z}}+a_{4} \quad\left(0<e_{\mathrm{z}}<e_{\mathrm{z} 1}\right) \\
& \sigma=b_{1} e_{\mathrm{z}}^{3}+b_{2} e_{\mathrm{z}}^{2}+b_{3} e_{\mathrm{z}}+b_{4} \quad\left(e_{\mathrm{z} 1}<e_{\mathrm{z}}<e_{\mathrm{z} 2}\right) \\
& \sigma=c_{1} e_{\mathrm{z}}^{c 2} \quad\left(e_{\mathrm{z} 2}<e_{\mathrm{z}}<e_{\mathrm{z} 3}\right)
\end{aligned}
$$

Table 3 Stiffness coefficient values with Eqs. (1)-(3) (Jina et al., 2017).

\begin{tabular}{c|c|c|c|c|c|c|c}
\hline \hline$e_{\mathrm{z} 1}$ & 0.0835 & $e_{\mathrm{z} 2}$ & 0.178 & $e_{\mathrm{z} 3}$ & 2.192 & & \\
\hline$a_{1}$ & 14.1 & $a_{2}$ & -5.35 & $a_{3}$ & 0.71 & $a_{4}$ & 0.0006 \\
\hline$b_{1}$ & -0.56 & $b_{2}$ & 0.27 & $b_{3}$ & -0.04 & $b_{4}$ & 0.003 \\
\hline$c_{1}$ & 0.0015 & $c_{2}$ & -1.04 & & & & \\
\hline
\end{tabular}

In this user-defined subroutine, the bonding line force $f=\sigma L_{\text {ZDTT }}$ is specified by the stiffness $K$ and the distance $U$ between the first and second ends of the nonlinear spring, as shown in Eq. (4).

$$
\sigma=\left(K \cdot L_{\mathrm{ZDTT}}{ }^{-1}\right) \cdot U
$$

In the implementation of a user-defined subroutine, Eq. (4) was replaced with Eqs. (1)-(3) using $e_{\mathrm{z}}=U$. When $U>e_{\mathrm{z} 3}$, the nonlinear spring force is defined as zero. Namely, this is the breaking criteria based on the ZDTT model.

\subsection{Experimental initial creasing of specimens}

The specimens were prepared as 5 pieces of a rectangle formed white-coated paperboard, which had a width $W_{\mathrm{CST}}=$ $20 \mathrm{~mm}$ and length $L_{\mathrm{CST}}=40 \mathrm{~mm}$. All the paperboard specimens were kept in a temperature of $296 \pm 1 \mathrm{~K}$ and a relative humidity of $50 \% \pm 1 \%$ in a controlled room for $24 \mathrm{~h}$. The creasing stage was performed in the same room. Measurements were performed five times for each case. Figure 2 shows the scoring state of a paperboard specimen using a round-edge knife (a creasing rule with a radius of $r=0.355 \mathrm{~mm}$ and thickness of $b=0.71 \mathrm{~mm}$ ) with the rubber fixtures, of which the shore hardness was $40 \mathrm{~A}$. The height difference (step) of rubber from the creasing rule was $1.4 \mathrm{~mm}$, and the height of rubber was $7 \mathrm{~mm}$. Using the paperboard thickness $t$ and the thickness of the creasing rule $b$, the groove width $B$ was empirically chosen as $2 t+b=1.6 \mathrm{~mm}$. The paperboard was scored by the creasing rule with a changing indentation depth $d$. The quantity $\gamma=2 d / B$ is defined here as the normalized indentation depth (Kirwan, 2013; Nagasawa et al., 2015). The creaser direction angle $\phi$ was chosen as $90^{\circ}$ with respect to the MD, as shown in Fig. 3. The values of $\gamma$ were chosen as $0.4,0.7$ and 1.0. The feed velocity was chosen as $V=0.0167 \mathrm{~mm} \cdot \mathrm{s}^{-1}$. Figure 4 shows the depth and width profile of scoring process. Figure 4 (a) shows the indentation depth of creasing rule $d$, whereas Figure 4 (b) shows the profile after scoring, namely, the depth after scoring $d_{\text {as }}$ and the width after scoring $w_{\mathrm{p}}$. Table 4 shows the indentation depth of creasing rule $d$ and the profile parameters $d_{\text {as }}$ and $w_{\mathrm{p}}$ after scoring.

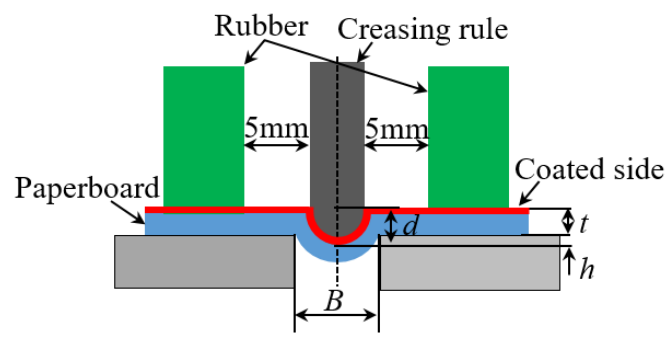

Fig. 2 Schematic of the scoring apparatus

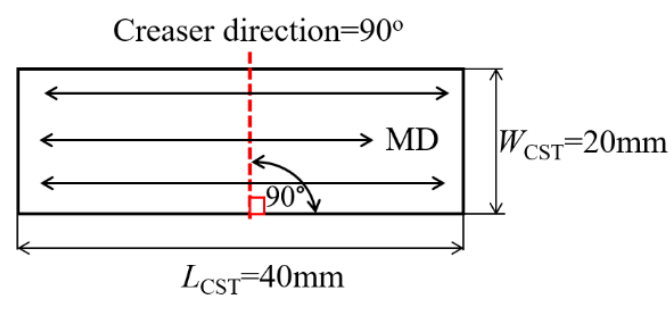

Fig. 3 Creaser direction of paperboard 


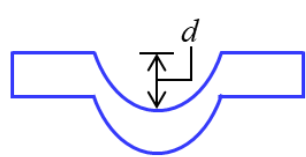

(a). Indentation depth before release the creasing blade $d$

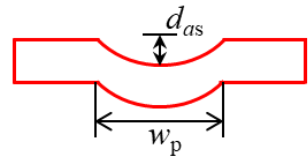

(b). Scoring profile after scoring stage $d_{\mathrm{as}}$ and width profile $w_{\mathrm{p}}$ after scoring process

Fig. 4 Depth and width profile of the scoring stage.

Table 4 Scoring profile of experiment.

\begin{tabular}{c|c|c|c}
\hline \hline \multirow{2}{*}{$\begin{array}{c}\text { Normalized indentation } \begin{array}{c}\text { Indentation depth } \\
\text { depth } \gamma\end{array} \\
\text { before release } d / \mathrm{mm}\end{array}$} & Depth $d_{\text {as }} / \mathrm{mm}$ & Width $w_{\mathrm{p}} / \mathrm{mm}$ \\
\hline 0.4 & 0.32 & $0.1(0.09-0.11)$ & $1.88(1.79-1.94)$ \\
\hline 0.7 & 0.56 & $0.2(0.18-0.2)$ & $1.97(1.79-2.08)$ \\
\hline 1.0 & 0.8 & $0.32(0.3-0.34)$ & $2.13(2.02-2.19)$ \\
\hline
\end{tabular}

\subsection{Experimental bending moment}

To estimate the bending resistance of a white-coated paperboard, the folding experiment of the cantilever type (CSTJ-1) was carried out. The specimen was taken over from the scoring stage described in section 2.3. The experiment was performed five times for each case. Figure 5 shows a schematic of the CST-J-1 apparatus (Nagasawa et al., 2011, 2015; Katayama Steel Rule Die., 2013), and the loading process and deformed state of the specimen are shown. Figure 6 is an example of the relation between the folding angle $\theta$ and the bending line moment (resistance for the unit width) $M$. Here, the rotation velocity $\omega$ of the fixture was set to $0.05 \mathrm{rps}$ and the folding angle was increased up to $90^{\circ}$. In order to compare later the simulation with the experiment, the moment $M_{90}$ (at $\theta=90^{\circ}$ ) was recorded.

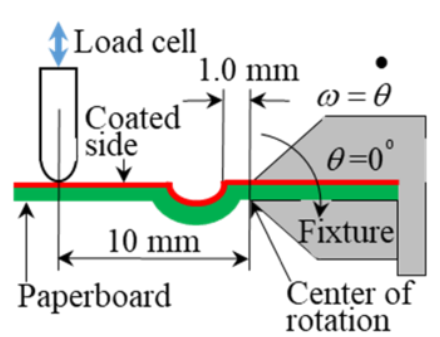

(a) Loading state of the specimen

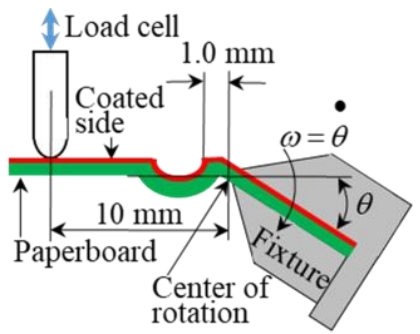

(b) Deformed state of the specimen

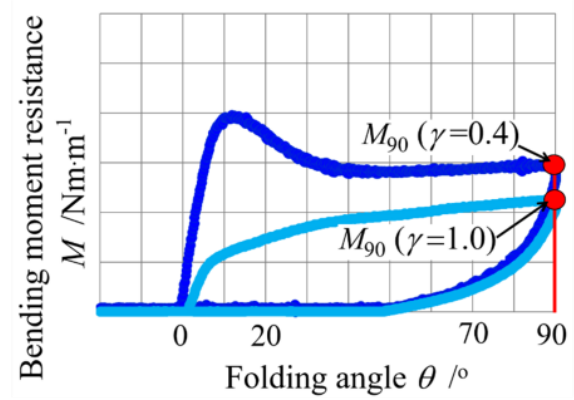

Fig. 5 Bending test apparatus using CST-J-1 (loading process). Fig. 6 Analysis parameters at tracking point of $90^{\circ}$ in the bending moment response.

\section{Estimation of in-plane shear strength properties}

The in-plane shear yielding stress test seems to be related to the creasing deformation. Therefore, the in-plane shear yielding test (based on ASTM-D3846-79, 1990) was conducted for estimating the breaking shear yielding stress under a free compressive state in the thickness direction. It seems to be a sort of a lower bound shear strength. On the other hand, the upper bound of shear strength is expected as the in-plane yielding shear stress of the worksheet. To investigate the lower bound shear strength, the MD direction was considered. Figure 7 shows the schematic of the shearing test apparatus and the specimen size. The specimen was fixed by an acrylic-based double-sided adhesive tape NWK-15S that was inserted between the metal plate and the worksheet. The velocity in the experiment of the shearing test was chosen as 0.1 $\mathrm{mm} \cdot \mathrm{s}^{-1}$. The specimens were prepared as 10 pieces of a rectangle sheet, the notches of which was made by a hand knife. The specimen had an effective length of $l_{\mathrm{dn}}=3 \mathrm{~mm}$ and a width of $w_{\mathrm{s}}=10 \mathrm{~mm}$. Namely, the nominal area of in-plane sheared zone was $30 \mathrm{~mm}^{2}$. The thickness of double-sided tape $t_{\mathrm{ds}}=0.14 \mathrm{~mm}$ and the thickness of metal plate $t_{\mathrm{m}}=0.22$ $\mathrm{mm}$ were used. The lower side of the metal plate was fixed, whereas the upper side of metal plate was pull up. Figure 8 shows the relation between the nominal shear stress $\tau=P /\left(w_{\mathrm{s}} l_{\mathrm{dn}}\right)$ and the displacement of the metal plate. In the figure, the shear strength $\tau_{\mathrm{B} \text { (inMD) }}$ (lower bound) was a breaking value recorded as the maximum $\tau_{\mathrm{B}(\mathrm{inMD})}=1.63(1.23-2.03) \mathrm{MPa}$, whereas the in-plane MD shearing yield strength (upper bound) was estimated as $\sigma_{\mathrm{Y}} / 1.732=15.7 \mathrm{MPa}$ from Table 2 . The strain energy with areal density until the breakage was roughly estimated as $2.2 \mathrm{~J} \cdot \mathrm{mm}^{2}$ from Fig. 8 .

In this work, due to the use of a general purpose FEM code (MSC.MARC 2015), the shear-stress-yield-based glue 
model was employed. Since the normal breaking resistance of delaminated layers is considered as the fluffing resistance (ZDTT based nonlinear spring model), only the shear resistance of delaminated layers is considered as the glue breaking model, which is controlled by the GLUED CONTACT option (MSC software, 2010a). The glued contact is generally released when Eq. (5) is satisfied. Here, $\tau_{\mathrm{if}}$ and $\sigma_{\mathrm{if}}$ are the contact shear and normal stress, respectively. $s_{\mathrm{t}}, s_{\mathrm{n}}$, and $m$ are the user-defined parameters of breakage. In this model, the normal resistance $s_{n}$ was not considered due to the use of fluffing model, and then the index of $m$ becomes arbitrarily determined.

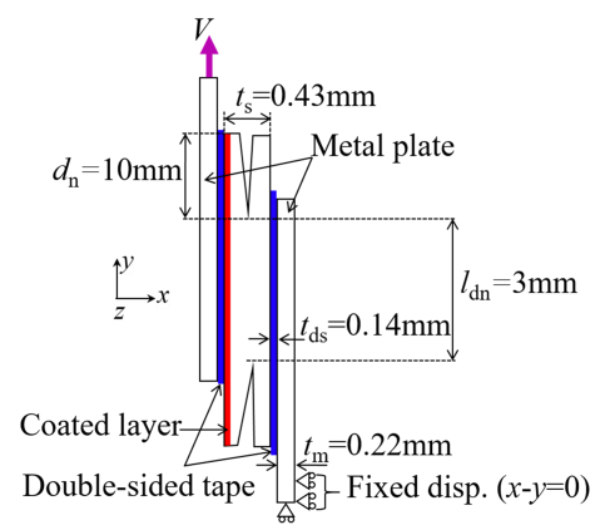

Fig. 7 Schematic of the shearing test apparatus

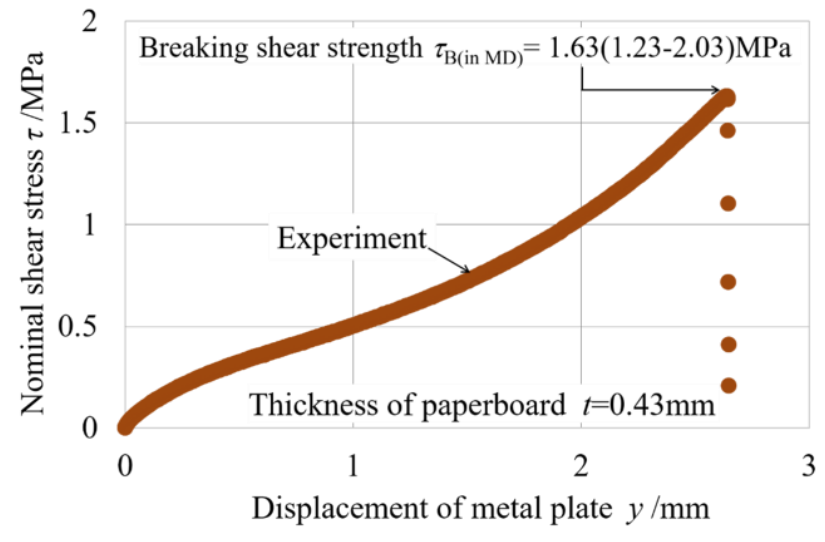

Fig. 8 Relation between the nominal shear stress and displacement of the metal plate in the in-plane shearing test

When any node is released on the delaminated layer due to the breaking criteria of Eq. (6), the node on the delaminated layer obeys the rule of frictional CONTACT (MSC software, 2010a) between the two bodies (upper/lower layers). The contact stress is calculated using the contact force divided by equivalent areas for shell elements. The glue breaking criteria was fundamentally defined by the in-plane shear stress of the shearing test. Therefore, $s_{\mathrm{t}}=1.63 \mathrm{MPa}$ was assumed to be the first trial value. However, due to the stress concentration at the cracked edge and the frictional restriction under a compressive-strained state, the macroscopic deformation of the creased zone must be verified using an appropriate amplified factor of the shear strength parameter $s_{\mathrm{t}}$. In the following simulation, the early stage slipping pattern of the delamination of interlayers and the saturated bending moment resistance at a large folded state (e.g., at $\left.\theta=90^{\circ}\right)$ are verified by varying the shear strength parameter $s_{\mathrm{t}}=1.63-16 \mathrm{MPa}$.

$$
\begin{aligned}
& \left(\sigma_{\mathrm{if}} / s_{\mathrm{n}}\right)^{m}+\left(\tau_{\mathrm{if}} / s_{\mathrm{t}}\right)^{m}=1 \\
& \left(\tau_{\mathrm{if}} / s_{\mathrm{t}}\right)=1
\end{aligned}
$$

\section{FEM simulation model}

\subsection{FEM simulation model for scoring}

A general purpose finite element code, MSC.MARC 2015, was employed for simulating the scoring process. The updated Lagrange procedure and a large strain analysis were used for a two dimensional model (plane strain). The thickness of the worksheet was $t=0.43 \mathrm{~mm}$. Figure 9 shows the FEM scoring model based on the experimental scoring process. Since the bending is two dimensional (plane strain), an isotropic elasto-plastic model was assumed by using the in-plane tensile testing properties in the MD. The mesh model was made of a full model, because the folding deformation was not symmetric with the scored-center position. Although the mechanical properties of thickness direction are different from this isotropic model, since the scored zone is initially de-laminated and the geometrical profile is fitted to the real experimental scored depth, the bending resistance seem to be characterized by the in-plane stiffness and resistance. Here, the layer detaching resistance is considered as the bonding resistance, and the bending resistance of each layer is characterized by the in-plane yielding stress. Although the number of plies were 8 for the considered specimens, the model of delamination layers assumed 3,5, 7 and 8 layers for verifying the effects of layer numbers as shown in Table 5. The upper layer defined as the 1st layer had the thickness of $c_{\mathrm{b}}=0.11 \mathrm{~mm}$ (Jina et al., 2017), whereas the other layers were defined as the following four cases: (1) Interlayers comprised 2nd and 3rd layers of $0.16 \mathrm{~mm}$. (2) Interlayers comprised 2nd-5th layers of $0.08 \mathrm{~mm}$. (3) Interlayers comprised 2nd-7th layers of $0.053 \mathrm{~mm}$. (4) Interlayers comprised 
2nd-8th layers of $0.046 \mathrm{~mm}$. Here, since the representative coated paperboard of $360 \mathrm{~g} \cdot \mathrm{m}^{-2}$ empirically has 8 layers in the paper making process, the fourth case was mainly used in the following simulation.

The breaking criteria of the bonded interfaces in the creasing zone were based on the fluffing model and the shear breaking glue model. Namely, a new combination model was introduced. The subroutine USPRNG that described the detaching resistance of ZDTT with Eqs. (1)-(3) was adopted. The shear breaking glue model was assumed to have the glue tangential strength parameter $s_{\mathrm{t}}$ chosen as five cases: $1.63 \mathrm{MPa}$ (as the lower bound strength based on the in-plane shearing test); $6 \mathrm{MPa}(3.7$ times of $1.63 \mathrm{MPa}) ; 11 \mathrm{MPa}(6.8$ times of $1.63 \mathrm{MPa}) ; 14 \mathrm{MPa}(8.6$ times of $1.63 \mathrm{MPa})$; and 16 $\mathrm{MPa}$ (10 times of $1.63 \mathrm{MPa}$, also estimated as the Mises shear yield of $\sigma_{\mathrm{Y}} / 1.732=15.7 \mathrm{MPa}$ ).

The size of specimen and boundary condition was shown in Fig. 9. The longitudinal length was assumed to be $L_{\mathrm{CST}}$ $=25 \mathrm{~mm}$. The number of divided elements of the worksheet was 16949, whereas that of the total nodes was 66843. The eight-node plane strain quadrilateral element type 27 was adopted. The Young's modulus of the deformable body was assumed to be $5400 \mathrm{MPa}$ from Table 2, and the Poisson's ratio was $v=0.2$ (Baum et al., 1981). The yield stress was assumed to be $27.2 \mathrm{MPa}$ (Table 2) and perfect-plastic. The deformable body comprised two parts: (1) Each layer was permanently fixed at the left and right outside and (2) Each layer was bonded by the USPRING joints of Eq. (4) and the shear glue of Eq. (6) at the central creased zone. The tools were assumed to be rigid bodies as following: creasing rule (round-edge knife), die (grooved counter plate) and rubber fixtures.

Regarding the friction coefficient of tools and worksheet, the kinetic friction coefficient between the noncoated paperboard and the counter plate was 0.4 (Murayama et al., 2005). The friction coefficient of the postal cardboard against the postal cardboard was also measured as 0.5-0.7 (Nagasawa et al., 2009). In this simulation work, to avoid any unstable state of FEM execution, all the friction coefficients were assumed to be appropriate values for each area as shown in Table 5. The friction coefficient $\mu_{\mathrm{el}}$ with the interlayers of the paperboard was 0.7 . The sliding condition of contact area against the tools was assumed to be slippery. Namely, the friction coefficients $\mu_{\mathrm{b}}, \mu_{\mathrm{d}}$ of the creasing rule and the grooved plate (channel die) against the paperboard were 0.1 . The friction coefficient $\mu_{\mathrm{r}}$ of the rubber fixture against the paperboard was assumed to be zero (no friction). The edge radius of groove was $0.1 \mathrm{~mm}$, whereas the width of groove (channel die) was $1.6 \mathrm{~mm}$. The lower grooved counter plate (die) was fixed, as shown in the vertical and horizontal axes (x, y-axis) in Fig. 9.

The indentation depth of the creasing rule was chosen as shown in Table 6. Seeing Table 4, the indentation depth of creasing rule $d$, and the permanent depth after scoring $d_{\text {as }}$ were fairly different with each other due to the spring back effect. It seems to be caused by the in-plane isotropic assumption of elasto-plastic behavior against the real orthotropic behavior. In order to compare the experimental result and the simulation, the permanent scoring depth based on the experimental result was approximately prepared in the simulation: $d_{\mathrm{as}}=0.1,0.2$ and $0.32 \mathrm{~mm}$. These parameters $d_{\mathrm{as}}$ were used in the simulation for discussing the cantilever type (CST-J-1) folding as shown in Table 6. Since the length of the detached zone was not known previously, it was chosen as $L=1.6$ (based on the width of channel die), 2.4 and $6.2 \mathrm{~mm}$ for investigating the effects of detached zone on the creasing deformation. Here, the $d_{\mathrm{as}}=0.2 \mathrm{~mm}$ was chosen as the representative case for the simulation of folding process.

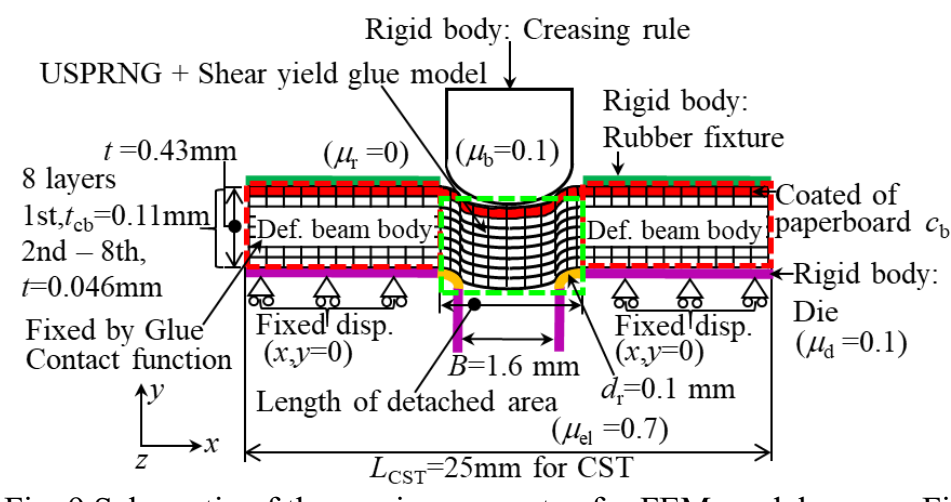

Fig. 9 Schematic of the scoring apparatus for FEM model.

The bonding restriction on the specified of the detaching layer (creasing area) was modeled by the user's subroutine USPRNG using the criteria of Eqs. (1)-(3) and the shear yield glue model.

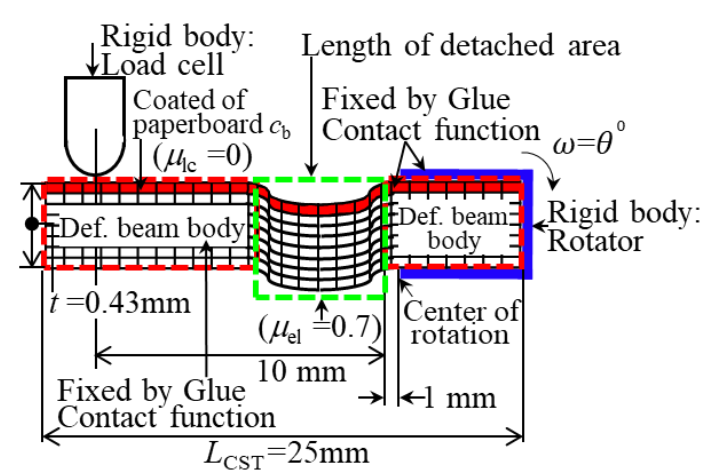

Fig. 10 Size definition and boundary condition of FEM CST model. The detaching layer (creasingarea) based on the user's subroutine USPRNG using the criteria of Eqs. (1)-(3) and the shear yield glue model. 
Table 5 Model conditions for FEM simulation.

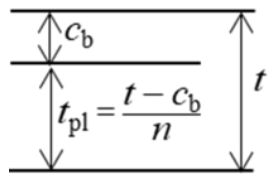

Definition of the thickness of interlayers when assuming $(n+1)$ plies

\begin{tabular}{|c|c|c|}
\hline Object type & Worksheet & \multirow{4}{*}{$\begin{array}{l}\text { Friction coefficients: } \\
\mu_{\mathrm{el}}=0.7 \\
\mu_{\mathrm{b}}, \mu_{\mathrm{d}}=0.1 \\
\mu_{\mathrm{r}}, \mu_{\mathrm{lc}}=0 \text { (no friction) }\end{array}$} \\
\hline Young's modulus E/MPa & 5400 & \\
\hline Poisson's ratio & 0.2 & \\
\hline Yield strength $\sigma_{\mathrm{Y}} / \mathrm{MPa}$ & 27.2 & \\
\hline Thickness of worksheet $t / \mathrm{mm}$ & 0.43 & \multirow{3}{*}{$\begin{array}{l}\text { Shear strength parameter of } \\
\text { glue joint: } \\
S_{\mathrm{t}}=1.63,6.0,11.0,14.0 \\
\text { and } 16.0 \quad / \mathrm{MPa}\end{array}$} \\
\hline Thickness of 1 st layer $c_{b} / \mathrm{mm}$ & 0.11 & \\
\hline $\begin{array}{l}t_{\mathrm{pl}} / \mathrm{mm} \text { for } 2 \mathrm{nd}-3 \mathrm{rd} \text { layers, } \\
\text { in case of } n=2\end{array}$ & 0.16 & \\
\hline $\begin{array}{l}t_{\mathrm{pl}} / \mathrm{mm} \text { for } 2 \mathrm{nd}-5 \text { th layers, } \\
\text { in case of } n=4\end{array}$ & 0.08 & \multirow{3}{*}{$\begin{array}{l}\text { Length of the detached zone: } \\
\qquad L=1.6,2.4,6.2 / \mathrm{mm}\end{array}$} \\
\hline $\begin{array}{l}t_{\mathrm{pl}} / \mathrm{mm} \text { for } 2 \mathrm{nd}-7 \text { th layers, } \\
\text { in case of } n=6\end{array}$ & 0.053 & \\
\hline $\begin{array}{l}t_{\mathrm{pl}} / \mathrm{mm} \text { for } 2 \mathrm{nd}-8 \mathrm{th} \text { layers, } \\
\text { in case of } n=7\end{array}$ & 0.046 & \\
\hline
\end{tabular}

Table 6 Scoring profile of FEM.

\begin{tabular}{c|c|c}
\hline \hline \multirow{2}{*}{$\begin{array}{c}\text { Indentation depth } \\
\text { before release } d / \mathrm{mm}\end{array}$} & \multicolumn{2}{|c}{ Profile after scoring } \\
\cline { 2 - 3 } & Depth $d_{\mathrm{as}} / \mathrm{mm}$ & Width $w_{\mathrm{p}} / \mathrm{mm}$ \\
\hline 0.13 & 0.1 & 1.64 \\
\hline 0.23 & 0.2 & 1.65 \\
\hline 0.35 & 0.32 & 1.61 \\
\hline
\end{tabular}

\subsection{FEM simulation model for folding}

In order to compare with the experimental observations described in section 2.4 and to predict the behavior of bending and bulging of creased part, a cantilever type (CST-J-1) folding was carried out as shown in Fig. 10. This simulation was taken over from the scoring stage described in section 4.1. Additional conditions were as follows: the friction coefficient of the load cell end of bending tester CST-J-1 against the paperboard $\mu_{\mathrm{cc}}$ was 0 (no friction), the arm length between the center of rotator and the load cell end was $10 \mathrm{~mm}$, the rotator fastened the deformable body and they were fixed by using the GLUE CONTACT function. Here, the load cell and rotator were assumed to be rigid bodies. The angular displacement of the rotator was up to $90^{\circ}$ on the clockwise ( -1.57 radians), the incremental angle was chosen as 0.0157 radians for each step in the simulation. The total increment was 100 steps for simulating the folding stage.

The simulation was discussed with respect to the next two categories: (C1) First, in order to verify the necessity of combination of the fluffing normal and the shear glue strength with the detaching resistance in the interlayers, the scored depth $d_{\text {as }}$ was chosen as $0.1,0.2$ and $0.32 \mathrm{~mm}$, and the length of the delaminated zone was chosen as $L=2.4 \mathrm{~mm}(1.5$ times of channel die width). Comparison of $d_{\mathrm{as}}$ was done for verifying the applicability of this combination model. The number of delamination layers was chosen as 3,5,7 and 8 layers, and the effect of layer numbers was discussed. Here, the 8 layers model was mainly used as the representative case. Regarding the magnitude of in-plane shear glue strength, the shear strength parameter $s_{\mathrm{t}}$ was chosen as $1.63,6.0,11.0,14.0$ and 16.0 MPa, respectively. (C2) In the second, to customize the size of delaminated zone, the length of the delaminated zone was chosen as $L=1.6$ (based on the width of channel die), 2.4 and $6.2 \mathrm{~mm}$. Here, the scored depth $d_{\text {as }}$ was chosen as $0.2 \mathrm{~mm}$, while the number of delamination layers was chosen as 8 .

\section{Results and discussion}

\subsection{Experimental bending moment resistance with the scoring depth}

Figure 11 shows the experimental relationship between the bending moment resistance $M$ and folding angle $\theta$ when choosing the scored depth $d_{\text {as }}=0.1,0.2$ and $0.32 \mathrm{~mm}$. The bending moment resistance tended to decrease with the scored depth $d_{\text {as }}$. Figure 12 shows the sectional views of creased part of experimental specimens folded at $\theta=20^{\circ}$ and $90^{\circ}$. Here, the case of $d_{\mathrm{as}}=0.1 \mathrm{~mm}$ was shown in the subfigures (a) and (b), the case of $d_{\mathrm{as}}=0.2 \mathrm{~mm}$ was shown in the subfigures (c) and (d), the case of $d_{\mathrm{as}}=0.32 \mathrm{~mm}$ was shown in the subfigures (e) and (f), respectively. 


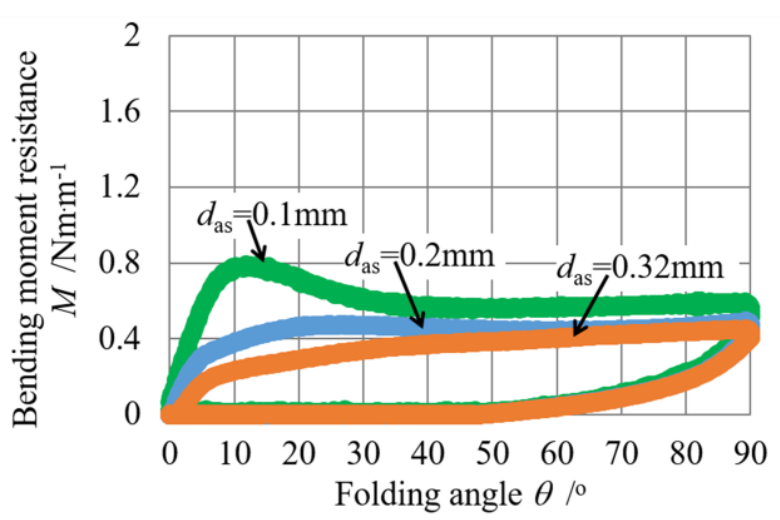

Fig. 11 Relationship between bending moment resistance and folding angle in the experiment when choosing $d_{\mathrm{as}}=0.1,0.2$, and $0.32 \mathrm{~mm}$.

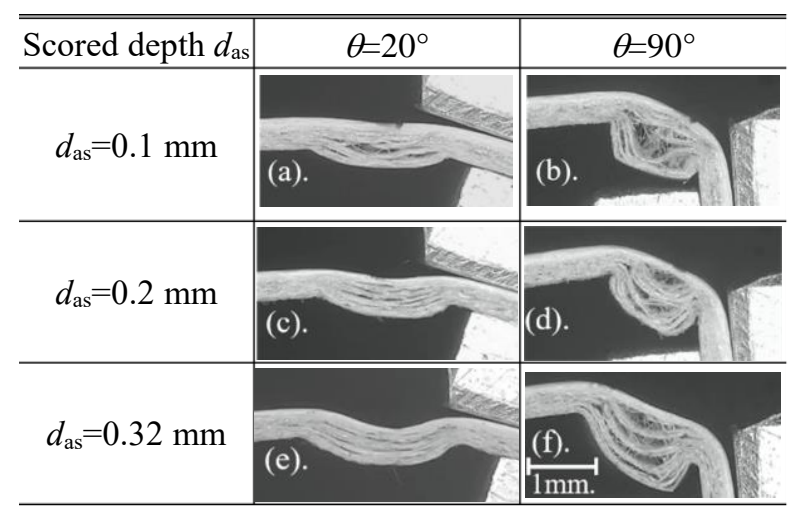

Fig. 12 Sectional views of creased part of paperboard in the experiment when folding at $\theta=20^{\circ}$ and $90^{\circ}$. Photographs were arranged in: (a) and (b) as $d_{\mathrm{as}}=0.1 \mathrm{~mm}$, (c) and (d) as $d_{\mathrm{as}}=0.2 \mathrm{~mm}$, and (e) and (f) as $d_{\mathrm{as}}=0.32 \mathrm{~mm}$.

\subsection{Combination effect of shear glue strength and fluffing normal strength}

The case $\mathrm{C} 1$ described in section 4.2 was investigated. Figure 13 shows the relationship between bending moment resistance $M$ and folding angle $\theta$ of the paperboard. Here, the permanent scored depth was representatively chosen as $d_{\mathrm{as}}=0.1 \mathrm{~mm}$ in the experiment and FEM simulation. Here, the experimental result was referred from Fig. 11 . Figure 14 shows the relationship between bending moment resistance $M_{90}$ at $\theta=90^{\circ}$ and shear strength parameter $s_{\mathrm{t}}$. When choosing $s_{\mathrm{t}}=11 \mathrm{MPa}$ for $90^{\circ}>\theta>20^{\circ}$, the FEM simulation based bending moment almost matched that of experimental result. However, when choosing $s_{\mathrm{t}}>14 \mathrm{MPa}$, the FEM simulation based bending moment tended to be remarkably larger than that of experiment, owing that any detaching deformation disappeared at the scored zone and then there was not appropriate bulging.
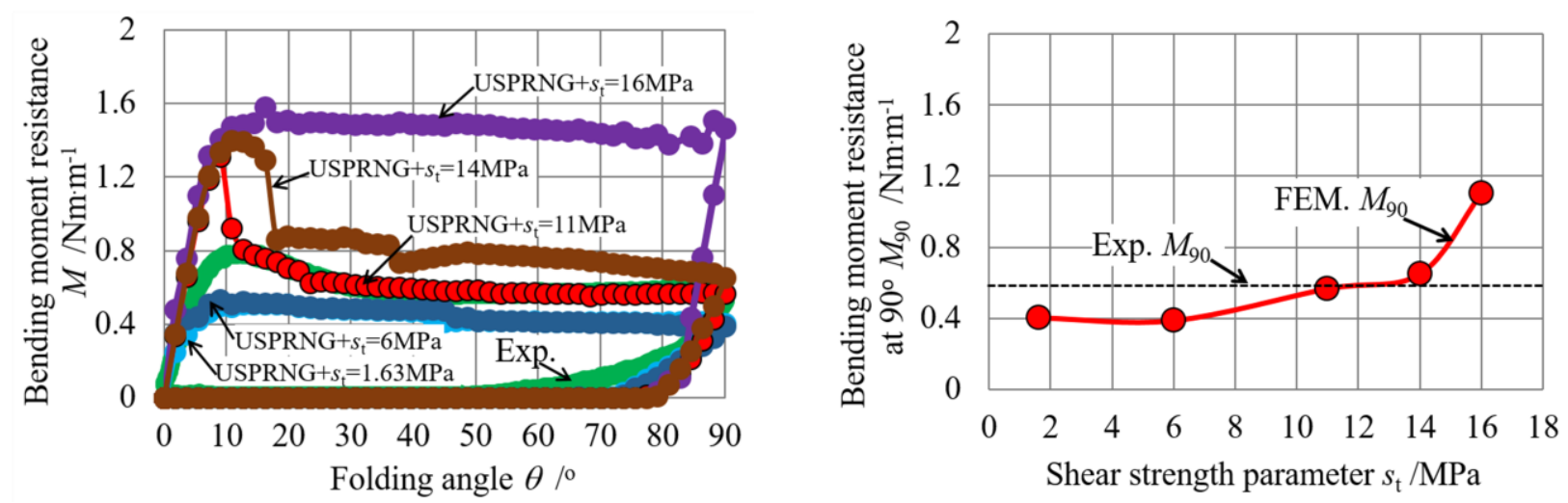

Fig. 13 Relationship between bending moment resistance and Fig. 14 Relationship between bending moment resistance folding angle. Simulated conditions were as follow: the scored depth $d_{\mathrm{as}}=0.1 \mathrm{~mm}$, the number of layers 8 , the length of delaminated zone $L=2.4 \mathrm{~mm}$, and the detaching criteria was the fluffing plus the shear strength parameter and shear strength parameter $s_{\mathrm{t}}$ at the folding angle $90^{\circ}$. The simulated conditions were the same as that of Fig. 13. $s_{\mathrm{t}}=1.63,6.0,11.0,14.0$ and $16.0 \mathrm{MPa}$.

Figures 15 and 16 show contour band diagrams with the magnitude of the maximum (principal) shear stress $\tau_{\text {Pmax }}$ when choosing the shear strength parameter $s_{\mathrm{t}}$ as 1.63 and $11 \mathrm{MPa}$, respectively. In case of $s_{\mathrm{t}}=1.63 \mathrm{MPa}$, as shown in Fig. 15, the bulge of scored part was obviously insufficient compared with that of the experimental result shown in Fig. 12 (b). In case of $s_{\mathrm{t}}=11 \mathrm{MPa}$, as shown in Fig. 16, the bulge of scored part was relatively similar to that of experimental result. Seeing these contour band diagrams, the Mises shear stress (yielding level) of $15.7 \mathrm{MPa}=\sigma_{\mathrm{y}} / \sqrt{3}$ occurred at the contact zone of interlayers in both cases. This seems to be caused by the frictional shear sliding under a high pressured 
contact with the interlayers. Namely, it is found that the shear strength parameter $s_{\mathrm{t}}$ does not determine the maximum shear stress, but affects the early stage slipped pattern of interlayers. In this work, $s_{\mathrm{t}} / \tau_{\mathrm{B}(\mathrm{inMD})}=6.7$ was relatively suitable for making the bulging profile and the saturated bending moment resistance $M_{90}$.

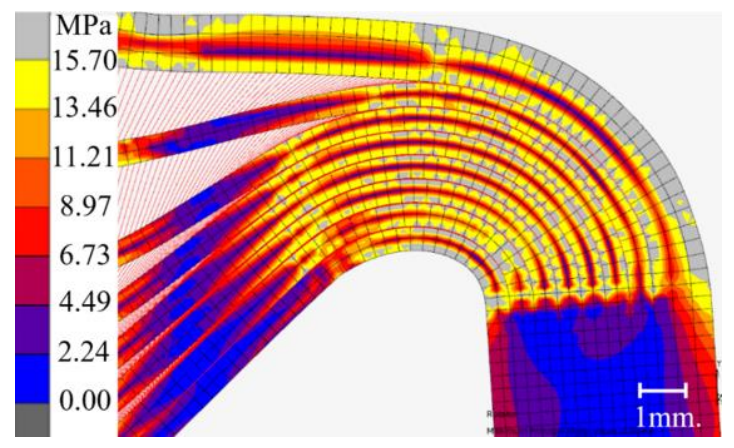

Fig. 15 Contour bands diagram of the maximum shear stress $\tau_{\text {Pmax }}$ when choosing $s_{\mathrm{t}}=1.63 \mathrm{MPa}$ for the folding angle of $90^{\circ}$. Other simulated conditions were as follows: the scored depth $d_{\mathrm{as}}=0.1 \mathrm{~mm}$, the length of delamination zone $L=2.4 \mathrm{~mm}$, and the detaching criteria was the fluffing plus the shear strength

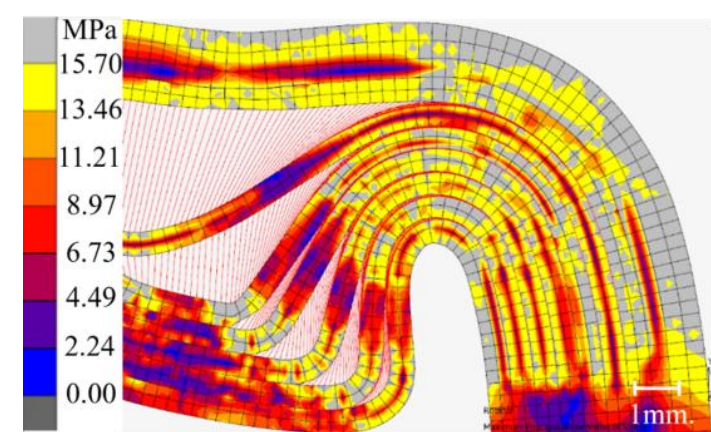

Fig. 16 Contour bands diagram of the maximum shear stress $\tau_{\text {Pmax }}$ when choosing $s_{\mathrm{t}}=11.0 \mathrm{MPa}$ for the folding angle of $90^{\circ}$. Other simulated conditions were as follows: the scored depth $d_{\mathrm{as}}=0.1 \mathrm{~mm}$, the length of delamination zone $L=2.4 \mathrm{~mm}$, and detaching criteria was the fluffing plus the shear strength

Seeing the cases of $s_{\mathrm{t}}>11 \mathrm{MPa}$ in Fig.13, the simulated response had a large overshoot at the early stage $\left(\theta=10 \sim 20^{\circ}\right)$, whereas the experimental result had not such an overshoot response. This numerical overshoot appeared to be caused by bulging of scored zone due to the use of the isotropic elasto-plastic model based on the tensile test in the MD. Although the scored zone of specimen seemed to be soften by the indentation of creasing rule, the FEM model used the in-plane tensile test properties for all the range of specimen.

Seeing the bending moment response at the early stage $\left(\theta<10^{\circ}\right)$ in Fig. 13, the initial gradient $G_{\mathrm{i}}=\partial M / \partial \theta$ (for 0 $<\theta<2^{\circ}$ ) of simulation appeared to be a little larger than that of experiment, although $G_{\mathrm{i}}$ is almost independent to $S_{\mathrm{t}}$. In order to reveal the effect of permanent scored depth $d_{\text {as }}$ on the folding deformation of creased paperboard, the initial gradient $G_{\mathrm{i}}$ and the saturated bending moment $M_{90}$ was investigated. According to the experimental reports, $G_{\mathrm{i}}$ and $M_{90}$ tended to be decreased with $\gamma=0.2-1.0$ (Nagasawa et al., 2001, 2003).

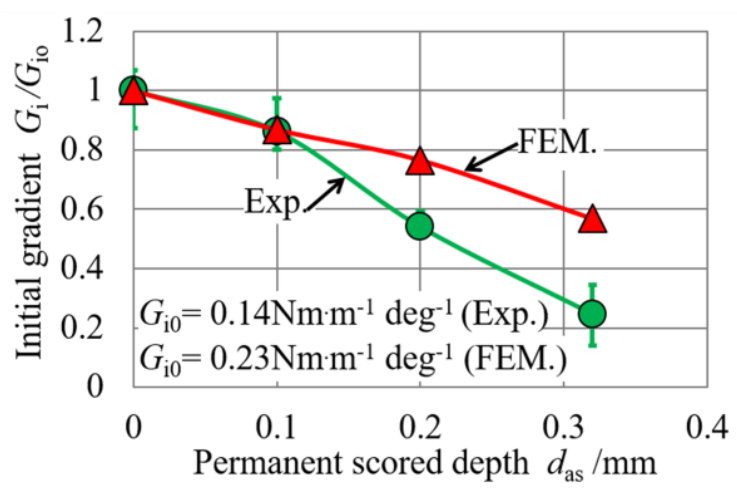

Fig. 17 Effect of permanent scored depth $d_{\mathrm{as}}$ on the initial gradient of bending moment. In the FEM simulation, the length of de-lamination area was $L$ $=2.4 \mathrm{~mm}$, and detaching criteria was based on the fluffing plus shear glue of $s_{\mathrm{t}}=11.0 \mathrm{MPa}$.

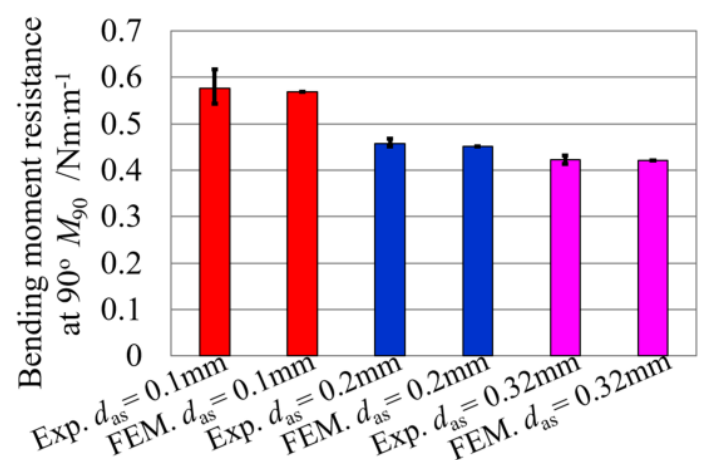

Fig. 18 Relationship between bending moment resistance at the folding angle of $90^{\circ}$ for experiment and FEM simulation. The scored depth was $d_{\mathrm{as}}=0.1,0.2$ and 0.32 $\mathrm{mm}$. In the FEM simulation, the length of de-lamination area was $L=2.4 \mathrm{~mm}$, and detaching criteria was based on the fluffing plus shear glue of $s_{\mathrm{t}}=11.0 \mathrm{MPa}$. 
Figure 17 shows the normalized initial gradient $G_{\mathrm{i}} / G_{\mathrm{i} 0}$ for $d_{\mathrm{as}}=0.1,0.2$ and $0.32 \mathrm{~mm}$. Here, in the FEM simulation, the shear parameter was $s_{\mathrm{t}}=11 \mathrm{MPa}$ and the delaminated zone was $L=2.4 \mathrm{~mm}$, and $G_{\mathrm{i} 0}$ was the initial gradient when $d_{\mathrm{as}}$ $=0$. The experimental $G_{\mathrm{i} 0}$ was $0.14 \mathrm{Nm} \cdot \mathrm{m}^{-1} \mathrm{deg}^{-1}$ and that of simulation model was $0.23 \mathrm{Nm} \cdot \mathrm{m}^{-1} \mathrm{deg}^{-1}$, respectively. Therefore, the initial stiffness of FEM model was about $60 \%$ larger than that of experiment, owing that the isotropic elasto-plastic model in in-plane MD was considered in the FEM model. Nevertheless, the FEM simulation and the experimental results had a similar dependency on $G_{\mathrm{i}}$ with that of the scored depth. Namely, the geometrical feature of scored depth is the primary factor for determining the initial gradient $G_{\mathrm{i}}$. Regarding the mismatching for $d_{\mathrm{as}}>0.2 \mathrm{~mm}$, the material properties (such as the Young's modulus and yielding stress) seem to be changed by deep indentation of creasing rule at the scored zone, and then a sort of the work softening seems to reduce the initial gradient actually.

Figure 18 shows the relationship between the bending moment resistance $M_{90}$ at the folding angle $90^{\circ}$ when choosing $d_{\mathrm{as}}=0.1,0.2$ and $0.32 \mathrm{~mm}$ under $s_{\mathrm{t}}=11 \mathrm{MPa}$. Comparing the FEM simulation with the experimental result for each scored depth, they were fairly matched with each other. So far, it is found that the determination procedure of the shear strength parameter $s_{\mathrm{t}}$ in the FEM simulation is applicable to the folding of creased paperboard when watching the saturated folding angle. In this work, the right angle folding was verified for $d_{\mathrm{as}}=0.1-0.32 \mathrm{~mm}$.

\subsection{Effects of lamination numbers}

Because the prepared paperboard had the thickness of $0.43 \mathrm{~mm}$ and its lamination numbers were empirically estimated as 8 layers, the FEM simulation was mainly discussed by using the 8 layers model. As the sensitivity of layer numbers on the bending stiffness seems to be important for designing or estimating the folding stiffness, the effects of layer numbers on the bending moment at the saturated state of $\theta=90^{\circ}$ were investigated here while virtually varying the layer numbers. Table 7 shows the experimental and FEM-simulated bending moment $M_{90}$ at $\theta=90^{\circ}$ when varying $d_{\text {as }}$ under $s_{\mathrm{t}}=11 \mathrm{MPa}$ when concerning the lamination numbers of 3, 5, 7 and 8 layers. From this table, the following features were disclosed: (1) When the lamination layers were 8 layers, $M_{90}$ of the FEM model almost agreed with that of experiment for $d_{\mathrm{as}}=0.1,0.2$ and $0.32 \mathrm{~mm}$. The 8 layer model seems to be suitable for the describing the bulging of paperboard. (2) When the lamination numbers was less than 8 layers, as the bending stiffness of each layer is remarkably increased (related to the cube of its thickness) and the freedoms of buckling of delaminated layer are changed, the saturated bending moment resistance $M_{90}$ seems to increase with decreasing layer numbers.

As the result, using the proposed model (isotropic, in-plane tensile properties based material properties, 8 layers with the combination detaching criteria by the fluffing resistance of Eq. (4) and shear glue resistance of $s_{\mathrm{t}}=11 \mathrm{MPa}$ ), the FEM simulation of bending moment response was similar to the experimental response for three kinds of scored depth: $d_{\text {as }}=$ $0.1,0.2$ and $0.32 \mathrm{~mm}$.

Table 7 Experimental and FEM based bending moment resistances $M_{90}$ with respect to $d_{\text {as }}$.

\begin{tabular}{c|c|c|c|c|c}
\hline \hline \multirow{2}{*}{ Depth $d_{\text {as }} / \mathrm{mm}$} & \multirow{2}{*}{ Experimental results $/ \mathrm{Nm}^{-1}$} & \multicolumn{4}{|c}{ FEM results $/ \mathrm{Nm}^{-1}$} \\
\cline { 3 - 6 } & & 3 layers & 5 layers & 7 layers & 8 layers \\
\hline 0.1 & $0.58(0.54-0.62)$ & 1.09 & 0.97 & 0.91 & 0.57 \\
\hline 0.2 & $0.46(0.45-0.47)$ & 1.0 & 0.88 & 0.8 & 0.45 \\
\hline 0.32 & $0.42(0.41-0.43)$ & 1.06 & 0.82 & 0.63 & 0.42 \\
\hline
\end{tabular}

\subsection{Bulged profile of the creased part}

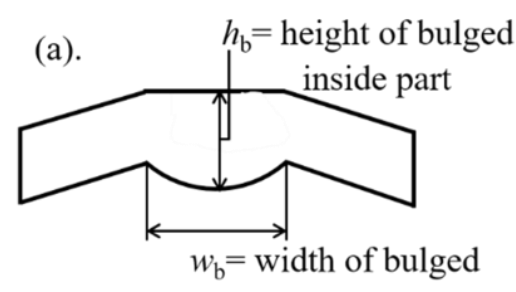

\begin{tabular}{c|l|l}
\hline \hline Scored depth $d_{\mathrm{as}}$ & $\theta=20^{\circ}$ & \multicolumn{1}{|c|}{$\theta=90^{\circ}$} \\
\hline$d_{\mathrm{as}}=0.1 \mathrm{~mm}$ & (b). & (c). \\
\hline$d_{\mathrm{as}}=0.2 \mathrm{~mm}$ & (d). & (e). \\
\hline
\end{tabular}

Fig. 19 Sectional views of folded part of paperboard in the FEM simulation with respect to $20^{\circ}$ and $90^{\circ}$. (a) Definition of the height and the width for bulged profile. (b) and (c): at $d_{\mathrm{as}}=0.1 \mathrm{~mm}$. (c) and (d): at $d_{\mathrm{as}}=0.2 \mathrm{~mm}$. In the FEM simulation, $L=2.4 \mathrm{~mm}$, the lamination was 8 layers, and the detaching criteria was based on the fluffing resistance plus shear glue of $s_{\mathrm{t}}=11 \mathrm{MPa}$. 
Figure 19 shows the sectional views of the FEM folded parts for the folding angle of $\theta=20^{\circ}, 90^{\circ}$. Fig. 19 (a) defines the height $h_{\mathrm{b}}$ and the width $w_{\mathrm{b}}$ of bulged inside part. Figure 19 (b)-(e) illustrated the FEM simulation result at the folding angle of $\theta=20,90^{\circ}$ when choosing the scored depth of $d_{\mathrm{as}}=0.1,0.2 \mathrm{~mm}$. Here, the FEM model conditions were as follow: the length of delaminated area was $L=2.4 \mathrm{~mm}$, the de-lamination resistance was considered as the fluffing model of USPRNG plus the shear glue parameter of $s_{\mathrm{t}}=11 \mathrm{MPa}$.

The FEM deformation profile well described the inside bulging and delamination state at the center zone for both the cases of $d_{\mathrm{as}}=0.1$ and $0.2 \mathrm{~mm}$. Figure 20 shows the height $h_{\mathrm{b}}$ and the width $w_{\mathrm{b}}$ of the bulged inside part of the experiment and the FEM simulation for the folding angle $\theta=20^{\circ}, 30^{\circ}, 50^{\circ}, 70^{\circ}$ and $90^{\circ}$, when choosing $d_{\mathrm{as}}=0.1 \mathrm{and} 0.2 \mathrm{~mm}$. Seeing this figure, the width $w_{\mathrm{b}}$ of FEM simulation was similar but a little smaller $(15 \%-24 \%)$ than that of the experiment for the folding angle of $20^{\circ}-90^{\circ}$, while the height $h_{\mathrm{b}}$ of FEM simulation was well matched to the experimental result for the folding angle. The case of $d_{\mathrm{as}}=0.32 \mathrm{~mm}$ were similar to the case of $d_{\mathrm{as}}=0.2 \mathrm{~mm}$, except for the gap extent of the width between the FEM simulation and experiment. Namely, the width of FEM simulation was a little smaller (20\%-26\%) than that of the experiment.
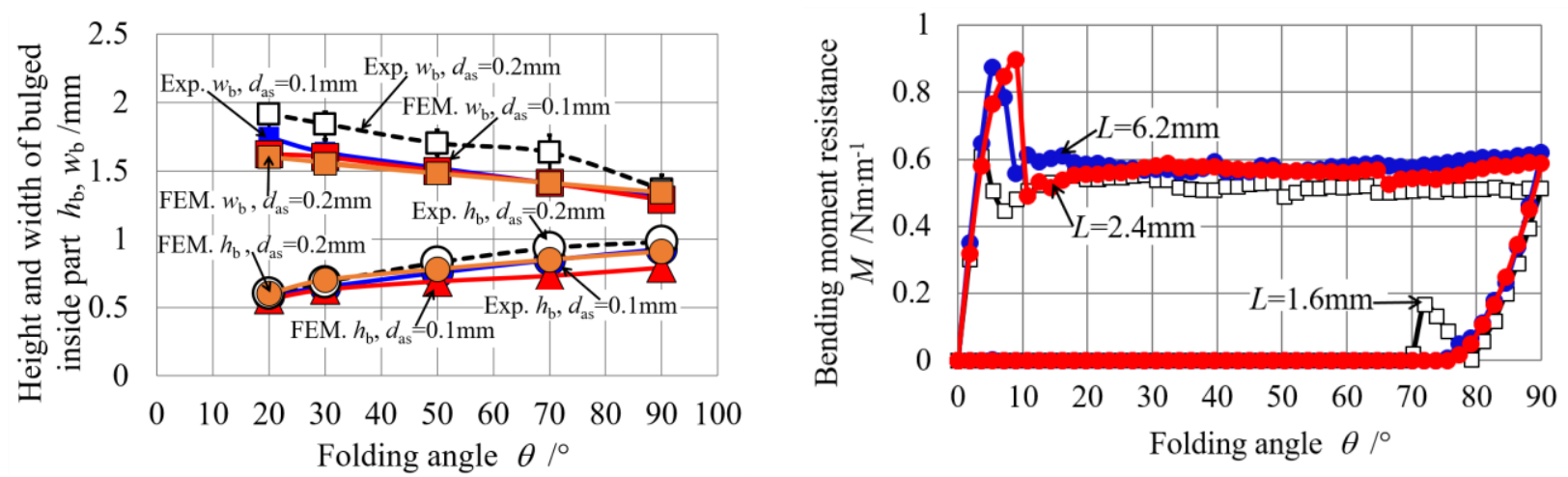

Fig. 20 Height and width of bulged inside profile with respect Fig. 21 Relation between bending moment resistance and to folding angle. In the FEM simulation, the length of delaminated area was $L=2.4 \mathrm{~mm}$, the lamination was 8 layers, the scored depth was $d_{\mathrm{as}}=0.1$ and $0.2 \mathrm{~mm}$, the detaching criteria was based on the fluffing plus shear glue of $s_{\mathrm{t}}=11 \mathrm{MPa}$.

folding angle in the FEM simulation. The lamination was 8 layers, the length of de-laminated area was chosen as $L=1.6$ (based on the width of channel die), 2.4 and $6.2 \mathrm{~mm}$. The scored depth was $d_{\mathrm{as}}=0.2 \mathrm{~mm}$, and the detaching criteria was based on the fluffing plus shear glue of $s_{\mathrm{t}}=11 \mathrm{MPa}$.

\subsection{Effects of length of delaminated zone}

In order to verify the effects of the delaminated zone on the folding deformation, the length of delamination zone was varied. Figure 21 shows the FEM bending moment resistance with the folding angle. Here, the length of the

\begin{tabular}{c|l|l}
\hline \hline $\begin{array}{c}\text { Length of de- } \\
\text { laminated area }\end{array}$ & $\theta=20^{\circ}$ & \\
\hline$L=1.6 \mathrm{~mm}$ & (a). & \\
\hline$L$ & & \\
\hline
\end{tabular}

Fig. 22 Sectional views of the folded part of FEM model.

(a)-(b): $L=1.6 \mathrm{~mm},(\mathrm{c})-(\mathrm{d}): L=2.4 \mathrm{~mm}$, and (e)-(f): $L=6.2 \mathrm{~mm}$, the scored depth was $d_{\mathrm{as}}=0.2 \mathrm{~mm}$, the lamination was 8 layers, and the detaching criteria was based on the fluffing plus the shear glue of $s_{\mathrm{t}}=11 \mathrm{MPa}$.

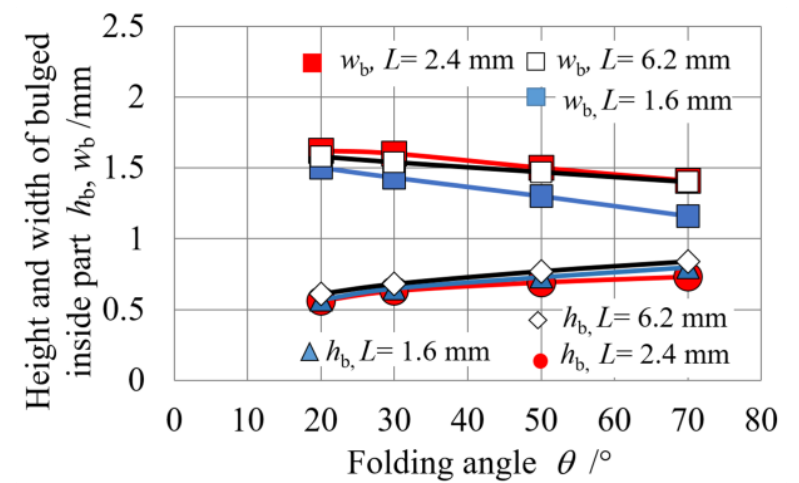

Fig. 23 Height and width of the bulged inside profile with respect to the folding angle. The scored depth was $d_{\mathrm{as}}=$ $0.2 \mathrm{~mm}$, the length of delaminated area was chosen as $L$ $=1.6,2.4$, and $6.2 \mathrm{~mm}$, the lamination was 8 layers, the detaching criteria was based on the fluffing plus the shear glue of $s_{\mathrm{t}}=11 \mathrm{MPa}$. 
delaminated zone was chosen as $L=1.6 \mathrm{~mm}$ (based on the width of channel die), $2.4 \mathrm{~mm}$ and $6.2 \mathrm{~mm}$. The scored depth was chosen as $d_{\mathrm{as}}=0.2 \mathrm{~mm}$, and the breaking criteria was based on the fluffing model of USPRNG plus the shear glue parameter of $s_{\mathrm{t}}=11 \mathrm{MPa}$. Seeing this figure, the saturated bending moments appeared to be similar to each other. Figure 22 shows the sectional views of folded part at the folding angle $\theta=20^{\circ}$ and $70^{\circ}$, while Fig. 23 shows the height and the width of bulged inside profile for the folding angle $\theta=20^{\circ}, 30^{\circ}, 50^{\circ}$ and $70^{\circ}$.

Through the comparison of these three conditions $(L=1.6,2.4$ and $6.2 \mathrm{~mm})$, it was found that the effect of the length of delaminated area was a little different between the case of $L=1.6$ and $L=6.2 \mathrm{~mm}$, as shown in Fig. 22, while the deformation profile of $L=6.2 \mathrm{~mm}$ was similar to that of $L=2.4 \mathrm{~mm}$. The height of bulged inside part well matched for $L=1.6,2.4$ and $6.2 \mathrm{~mm}$. Synthetically, the length of delaminated zone ought to be chosen as $L / B>1.5(L>2.4 \mathrm{~mm})$.

\section{Conclusions}

The cantilever type folding test of a creased paperboard of $0.43-\mathrm{mm}$ thickness was experimentally and numerically performed by varying the indentation depth. The folding behavior of the 8 layers of the paperboard was discussed with respect to the detaching resistance based on the fluffing of ZDTT and the shear glue strength parameter $s_{\mathrm{t}}$. In the FEM model, the bending stiffness was modeled by the in-plane tensile characteristics, and the scored depth was varied to verify the bulging behavior of creased part. The features of the developed FEM model were revealed as follows:

(a) A combined model of the out-of-plane fluffing resistance and the in-plane shear glue resistance was developed using a general purpose FEM code for describing the detaching resistance of the delaminated layers of the paperboard. Using this combined model of detaching resistance, a paperboard with a thickness of $0.43 \mathrm{~mm}, 8$ layers of lamination and the in-plane tensile-based isotropic elasto-plastic properties in the MD of paper making, was scored with a certain scored depth $\left(d_{\mathrm{as}}=0.1,0.2\right.$ and $\left.0.32 \mathrm{~mm}\right)$ by a creasing rule and successfully folded until the right angle. The simulated bulging profile of creased part and its bending moment resistance well matched with the corresponding experimental results for the folding angle $20^{\circ}<\theta<90^{\circ}$.

(b) When the shear glue strength parameter $s_{\mathrm{t}}$ was assumed to be close to the Mises yield strength of the specimen, the delamination was not sufficiently promoted at the creased part, and the bending behavior of creased part was far from the real delamination and bulging. Because the in-plane shearing resistance was investigated as $\tau_{\mathrm{B}(\mathrm{inMD})}=1.63 \mathrm{MPa}$, while choosing $s_{\mathrm{t}} / \tau_{\mathrm{B} \text { (inMD) }}<4$, the bending moment was relatively small and the bulging pattern was different from the experiment. There was an appropriate value of shear glue strength parameter $s_{\mathrm{t}}$ for simulating the folding deformation of the creased paperboard. An appropriate shear glue strength parameter $s_{\mathrm{t}}$ was chosen as $s_{\mathrm{t}} / \tau_{\mathrm{B}(\mathrm{inMD})} \approx$ 6.7 for the scored depth of $d_{\text {as }}=0.1-0.32 \mathrm{~mm}$ when using the groove width of $B=1.6 \mathrm{~mm}$.

(c) The initial gradient of bending moment against the folding angle was characterized by the scored depth of the FEM simulation as well as that of the experimental result.

(d) In the FEM model, the span length $L$ of the initial delaminated area was not sensitive enough to determine the bulging and bending moment resistance under a folding process, if $L / B>1.5$. Here, $B$ is the groove width.

Regarding the chosen parameters for modelling, when considering the isotropic elasto-plastic model for estimating the bending of laminated structure, the initial delamination pattern and bulging mode should be compared with the experimental tendency. Under satisfying the bulging mode of folded portion, the distribution of tensile or compressive state is inspected and then appropriate material properties gotten from the similar mode can be used for modelling the scored paperboard.

\section{Nomenclature}

ZDTT: z-directional (out-of-plane) tensile test

MD: machine direction for paper making

$t$ : thickness of worksheet (paperboard) Its average was $0.43 \mathrm{~mm}$.

$t_{\text {p ZDTT: }}$ thickness of the weak-bonded layer $\quad$ Its was $0.11 \mathrm{~mm}$.

$L_{\text {ZDTT }}$ length of the specimen for ZDTT test The length was $10 \mathrm{~mm}$.

$B_{\text {ZDTT: }}$ width of the specimen for ZDTT test The width was $10 \mathrm{~mm}$.

$e_{z}=x$ : elongation in ZDTT

$\sigma:$ Tensile stress in ZDTT

$a_{1}-a_{4}, b_{1}-b_{4}$ and $c_{1}$ : coefficients of Eqs.(1)-(3)

$f_{\mathrm{ZDTT}}=\sigma L_{\mathrm{ZDTT}}$ : tensile line force in ZDTT

$\sigma_{\mathrm{Y}}$ : the yield stress of specimen in the in-plane MD 
$U$ : distance between the 1 st end and 2 nd end of nonlinear spring which is joined to nodes on the peeled layer

$K$ : stiffness of nonlinear spring in USPRNG subroutine

$V$ : experimental indentation velocity of creasing rule it was $0.0167 \mathrm{~mm} \cdot \mathrm{s}^{-1}$.

$l_{\mathrm{dn}}$ : distance or length between the end of both notches in the in-plane shearing test the length was $3 \mathrm{~mm}$.

$w_{\mathrm{s}}$ : the width of the specimen in an in-plane shearing test The length was $10 \mathrm{~mm}$.

$t_{\mathrm{s}}$ : thickness of paperboard of in-plane shearing test The thickness was $0.43 \mathrm{~mm}$.

$d_{\mathrm{n}}$ : depth of notches It was $10 \mathrm{~mm}$.

$t_{\mathrm{ds}}$ : thickness of double-sided tape of in-plane shearing test It was $0.14 \mathrm{~mm}$.

$t_{\mathrm{m}}$ : thickness of metal plate of in-plane shearing test It was $0.22 \mathrm{~mm}$.

$\tau_{\mathrm{B}(\mathrm{inMD})}$ : breaking shear strength in the in-plane MD shearing test, estimated as $\tau_{\mathrm{B}(\mathrm{inMD})}=1.63 \mathrm{MPa}$.

$s_{\mathrm{t}}$ : shear strength parameter in the glue contact function.

$L_{\mathrm{CST}}$ : length of the specimen for CST test The length was $40 \mathrm{~mm}$.

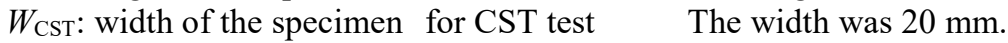

$B$ : width of channel die The width of channel die was $1.6 \mathrm{~mm}$.

$d$ : indentation depth of creasing rule

$d_{\mathrm{as}}$ : permanent depth after scoring by creasing rule.

$h$ : height difference (step) of rubber from the creasing rule It was $1.4 \mathrm{~mm}$.

$r$ : radius of a creasing rule The radius of creasing rule was $0.355 \mathrm{~mm}$.

$b$ : thickness of a creasing rule The thickness of creasing rule was $0.71 \mathrm{~mm}$.

$\gamma=2 d \cdot B^{-1}:$ normalized indentation depth (nominal shear strain)

$\theta$ : folding angle $\left(^{\circ}\right)$

$M$ : bending line moment resistance $=$ bending moment resistance per unit width against folding $\left(\mathrm{Nm} \cdot \mathrm{m}^{-1}\right)$

$M_{90}$ : bending line moment resistance at the folding angle of $\theta=90^{\circ}$, it was measured as the saturated state.

$\omega$ : rotation velocity of fixture for folding $(\mathrm{rps})\left(=2 \pi \omega \mathrm{rad} \cdot \mathrm{s}^{-1}\right) \quad$ It was set to $0.05 \mathrm{rps}$.

$c_{\mathrm{b}}$ : thickness of $1 \mathrm{st}$ layer of paperboard It was $0.11 \mathrm{~mm}\left(=t_{\mathrm{pZDTT}}\right)$.

$v$ : Poisson's ratio of paperboard It was assumed to be 0.2 .

$\mu_{\mathrm{b}}$ : friction coefficient between creasing rule and paperboard It was assumed to be 0.1 .

$\mu_{\mathrm{d}}$ : friction coefficient between grooved plate (die) and paperboard $\quad$ It was assumed to be 0.1 .

$\mu_{\mathrm{r}}$ : friction coefficient between paperboard and rubber fixtures It was assumed to be 0 (no friction).

$\mu_{\mathrm{el}}$ : friction coefficient between each layer (interface layer) of scoring area $\quad$ It was assumed to be 0.7 .

$\mu_{\mathrm{lc}}$ : friction coefficient between paperboard and pin of load cell It was assumed to be 0 (no friction).

\section{Acknowledgments}

This work was supported by a fund for developing a core of excellence as innovation and branding project, from the GIGAKU Innovation promotion center, NUT, 2014-2017.

\section{References}

American Society for Testing and Materials (ASTM), Standards and Literature References for Composite Materials, 2nd Ed. (1990), D3846-79.

Baum, G. A., Brennan, D. C. and Habeger, C. C., Orthotropic elastic constants of paper, Tappi Journal, Vol.64, No.8 (1981), pp.97-101.

Beex, L. A. A. and Peerlings, R. H. J., An experimental and computational study of laminated paperboard creasing and folding, International Journal of Solids and Structures, Vol.46, No.24 (2009), pp.4192-4207, DOI: 10.1016/j.ijsolstr.2009.08.012.

CST-J-1, Katayama Steel Rule Die Inc., Tokyo, Japan (online), available from < diemex.com/sale/cst_e.html $>$, (accessed on May, 2013).

Giampieri, A., Perego, U. and Borsari, R., A constitutive model for the mechanical response of the folding of creased paperboard, International Journal of Solids and Structures, Vol.48, (2011), pp.2275-2287, DOI: 10.1016/j.ijsolstr. 2011.04.002.

Hicks, B. J., Mullineux, G., Berry, C., McPherson, C. J. and Medland, A. J., Energy method for modelling delamination buckling in geometrically constrained systems, Proceedings of the Institution of Mechanical Engineers, Part C: Journal of Mechanical Engineering Science, Vol.217, (2003), pp.1015-1026, DOI: 10.1243/095440603322407254.

Jina, W., Nagasawa, S. and Chaijit, S., Estimation of detaching resistance of a peeled in-plane layer of a white-coated paperboard using fluffing resistance and an isotropic elasticity model, Journal of Advanced Mechanical Design, Systems, and Manufacturing, Vol.11, No.2 (2017), pp.1-12, DOI: 10.1299/jamdsm.2017jamdsm0018.

Kirwan, J. M., Handbook of Paper and Paperboard Packaging Technology, 2nd ed. (2013), pp.280-292, Wiley-Blackwell.

Komiyama, Y., Kon, W., Nagasawa, S. and Fukuzawa, Y., Effect of Structural Shape of Corrugated Medium on Flat Crush 
Characteristics of Corrugated Fiberboard, Journal of the Chinese Society of Mechanical Engineers, Transactions of the Chinese Institute of Engineers, Series C, Vol.34, No.4 (2013), pp.361-369.

MSC Software, Marc document: Theory and User Information), Vol. A, (2010a), pp.567-568, 655.

MSC Software, Marc document: User Subroutines and Special Routines), Vol.D, (2010b), pp.265-267.

Murayama, M., Nagasawa, S., Fukuzawa, Y., Yamaguchi, T. and Katayama, I., Orthotropic effect and strain dependency of paperboard on load characteristic of center bevel cutter indented on paperboard, Journal of Materials Processing Technology, Vol.159, (2005), pp.199-205, DOI:10.1016/j.jmatprotec.2004.03.033.

Nagasawa, S., Fukuzawa, Y., Yamaguchi, D., Nagae, S., Katayama, I. and Yoshizawa, A., Deformation characteristics of on creasing of paperboard under shallow indentation, Proceedings of 10th International Conference on Fracture (Advances in Fracture Research, Elsevier Sci.) (2001), Article ID: ICF10-0202-1-6, Hawaii, USA.

Nagasawa, S., Karasawa, M. and Fukuzawa, Y., Cutting characteristics of piled-up cardboards subjected to a wedge indentation, Journal of Japan Society for Technology of Plasticity, Vol.50, No.585 (2009), pp.946-950, DOI: 10.9773/sosei.50.946.

Nagasawa, S., Komiyama, Y. and Mitsomwang, P., Finite Element Analysis of Corrugated Board on Rotary Creasing Process, Journal of Advanced Mechanical Design, Systems, and Manufacturing, Vol.7, (2013a), pp.103-114, DOI: 10.1299/jamdsm.7.103.

Nagasawa, S., Mitsomwang, P., Chaijit, S. and Wongpatsa, W., Finite Element Analysis of Two Dimensional Deformation of Double-wall Corrugated Board on Creasing Process, Proceedings of the 3rd International Symposium on Engineering, Energy and Environments, Bangkok, (2013b), pp.338-343.

Nagasawa, S., Yamagata, D., Fukuzawa, Y. and Murayama, M., Stress analysis of wedged rupture in surface layer of coated paperboard, Journal of Materials Processing Technology Elsevier Science, Vol.178, (2006), pp.358-363, DOI: 10.1016/j.jmatprotec.2006.04.116.

Nagasawa, S., Nasruddin M. and Shiga, Y., Bending Moment Characteristics on Repeated Folding Motion of Coated Paperboard Scored by Round-Edge Knife, Journal of Advanced Mechanical Design, Systems, and Manufacturing, Vol.5, No.1 (2011), pp.385-394, DOI: 10.1299/jamdsm.5.385.

Nagasawa, S., Fukuzawa, Y., Yamaguchi, T., Tsukatani, S. and Katayama, I., Effect of crease depth and crease deviation on folding deformation characteristics of coated paperboard, Journal of Materials Processing Technology, Vol.140, (2003), pp.157-162, DOI: 10.1016/S0924-0136(03)00825-2.

Nagasawa, S., Endo, R., Fukuzawa ,Y., Uchino, S. and Katayama, I., Creasing characteristic of aluminum foil coated paperboard, Journal of Materials Processing Technology, Vol.201, (2008), pp.401-407. DOI:10.1016/j.jmatprotec.2007.11.253.

Nagasawa, S., Ozawa, S. and Fukuzawa, Y., Effects of folding numbers, scoring depth and bending velocity on bending-moment relaxation of creased paperboard, Mechanical Engineering Journal, Vol.2, No.1 (2015), pp.1-9, DOI: 10.1299/mej.1400346.

Nagasawa, S., Tran Xuan, Q. and Jina, W., Estimation of Bending Characteristics of Creased White-Coated Paperboard Subjected to In-Plane Compressive Load Using V-Block Fixtures, Modern Environmental Science and Engineering, Vol.2, No.4 (2016), pp.211-216, DOI: 10.15341/mese(2333-2581)/04.02.2016/001.

Reinhard, S., Werner, A., Werner, K. and Martin, T., Chapter 17 Surface Sizing and Coating, Handbook of paper and board (ed., Holik, H.), Vol.2, (2013), pp.747-772, WILEY-VCH Verlag and KGaA, Weinheim.

Sudo, A., Nagasawa, S., Fukuzawa, Y. and Katayama, I., Analysis of exfoliation of laminated layers and creasing deformation of paperboard, Proceedings of The Hokuriku-Shinetsu District Annual Conference of Japan Society of Mechanical Engineers, No.047-1, (2005), pp.35-36 (in Japanese), DOI: 10.1299/jsmehs.2005.42.35. 